\title{
Effects of flotation-restricted environmental stimulation technique on stress-related muscle pain: What makes the difference in therapy - attention-placebo or the relaxation response?
}

\author{
Sven A Bood MSc RN ${ }^{1}$, Ulf Sundequist $\mathrm{MA}^{2}$, Anette Kjellgren $\mathrm{PhD}^{2}$, \\ Gun Nordstrom $\mathrm{PhD}^{1}$, Torsten Norlander $\mathrm{PhD}^{3}$
}

SA Bood, U Sundequist, A Kjellgren, G Nordstrom, $\mathrm{T}$ Norlander. Effects of flotation-restricted environmental stimulation technique on stress-related muscle pain: What makes the difference in therapy - attention-placebo or the relaxation response? Pain Res Manage 2005;10(4):201-209.

INTRODUCTION: The purpose of the present study was to examine the potential effects of attention-placebo on flotation tank therapy. Flotation-restricted environmental stimulation technique is a method whereby an individual lies in a floating tank and all stimuli are reduced to a minimum.

METHODS: Thirty-two patients were diagnosed as having stressrelated muscular pain. In addition, 16 of the participants had received the diagnosis of burnout depression. The patients were treated with flotation-restricted environmental stimulation technique for six weeks. One-half of the patients were also given special attention for 12 weeks (high attention), while the remainder received attention for only six weeks (normal attention).

RESULTS: The participants exhibited lowered blood pressure, reduced pain, anxiety, depression, stress and negative affectivity, as well as increased optimism, energy and positive affectivity. The results were largely unaffected by the degree of attention-placebo or diagnosis. CONCLUSION: It was concluded that flotation therapy is an effective, noninvasive method for treating stress-related pain, and that the method is not more affected by placebo than by other methods currently used in pain treatment. The treatment of both burnout depression and pain related to muscle tension constitutes a major challenge for the patient as well as the care provider, an area in which great gains can be made if the treatment is effective. Flotation therapy may constitute an integral part of such treatment.

Key Words: Attention; Depression; Flotation-restricted environmental stimulation technique; Pain; Placebo; Relaxation response

$\mathbf{R}$ elaxation research has generated a number of subfields Rinvolving, for example, stretching and autogenic exercises (1), and mental and physical relaxation methods, such as Tai Chi (2). Further examples are offered with the aid of certain devices (ie, induced environmental settings), such as the physioacoustic method (3) and the flotation tank (4). The different relaxation techniques often lead to specific psychological and physiological changes labelled the 'relaxation response' (RR) (5). The RR is identified as the physiological counterpart of the stress or 'fight or flight' response (6). The RR is associated with
Les effets de la méthode REST par flottation sur la douleur musculaire reliée au stress : Ce qui fait la différence dans la thérapie - le placebo-attention ou la réponse de relaxation?

INTRODUCTION : L'étude visait à examiner les effets potentiels du placebo-attention sur la thérapie par bain flottant. La technique de stimulation environnementale réduite par flottation est une méthode selon laquelle un individu est couché dans un bain flottant et tous les stimuli sont réduits au minimum.

MÉTHODOLOGIE : Trente-deux patients avaient reçu un diagnostic de douleurs musculaires reliées au stress. Seize d'entre eux souffraient également d'épuisement professionnel diagnostiqué. Les patients ont été traités au moyen de la technique de stimulation environnementale réduite par flottation pendant six semaines. La moitié des patients ont également reçu une attention spéciale pendant 12 semaines (attention élevée), tandis que les autres n'en ont reçu que pendant six semaines (attention normale).

RÉSULTATS : Les participants affichaient une diminution de la tension artérielle, de la douleur, de l'anxiété, de la dépression, du stress et de l'affectivité négative, ainsi qu'une augmentation de l'optimisme, de l'énergie et de l'affectivité positive. Les résultats étaient en grande partie inchangés par le degré de placebo-attention ou le diagnostic.

CONCLUSION : On a conclu que la thérapie par flottation est une méthode efficace et non effractive pour traiter la douleur reliée au stress et qu'elle n'est pas plus influencée par un placebo que les autres méthodes utilisées pour traiter la douleur. Le traitement de l'épuisement professionnel et de la douleur reliée à la tension musculaire constitue un défi majeur pour les patients et pour le dispensateur de soins. C'est un domaine qui pourrait profiter d'avancées marquées si le traitement était efficace. La thérapie par flottation pourrait en faire partie intégrante.

instant physiological changes that include reduced sympathetic nervous system activity and metabolism, as well as lowered heart rate, blood pressure and respiratory rate $(7,8)$. At the psychological level, individuals typically experience the RR techniques as genuine rest, recovery, better sleep quality, less need for alcohol and psychoactive medication, as well as an increased sense of control and efficacy in stressful situations (9). According to Ben-Menachem (10), for a relaxation technique to successfully elicit the RR, at least two factors are necessary: reduced sensory input and reduced bodily movements.

${ }^{1}$ Department of Psychology, Department of Health and Caring Sciences; ${ }^{2}$ Human Performance Laboratory; ${ }^{3}$ Department of Psychology,

Karlstad University, Karlstad, Sweden

Correspondence and reprints: Dr Torsten Norlander, Department of Psychology, Karlstad University, SE-651 88 Karlstad, Sweden.

Telephone 46-54-700-11-78, fax 46-54-83-91-65, e-mail Torsten.Norlander@kau.se 
In the present study, a flotation tank was used to induce the RR. Flotation-restricted environmental stimulation technique (REST) is a method whereby an individual lies in a horizontally floating posture, immersed in salt water, in an environment (the flotation tank) in which all stimuli are reduced to a minimum. The salt water in the flotation tank is maintained at skin temperature and earplugs are used to minimize sounds. When the lid of the tank is closed, complete darkness ensues. Flotation-REST is a cost-effective and secure method with minimal or no adverse effects $(11,12)$.

Recent research with the flotation form of REST indicates that meaningful positive effects may be obtained. Such results include increased well-being and relaxation (13), mild euphoria $(14)$, greater production of ideas $(15,16)$, increased originality $(17,18)$, improved sleep at night $(19,20)$, reduced stress, tension and anxiety $(12,14,21-23)$, reduced pain $(20,24)$, fewer headaches (25), lowered blood pressure (21) and decreased muscle tension (26). It also constitutes a suitable complement to psychotherapy $(13,27)$; the method is described as pleasant and subjects eagerly endorse it on later occasions (28).

Extensive stress, without the possibility of recovery, frequently leads to both somatic and psychological symptoms (29-32) and burnout depression (33). Burnout depression typically begins with a sense of stress and overload (34). Individuals find it difficult to relax and difficult to fall asleep (35-37); they feel tense, revved up and irritable. Early on, individuals experience aches and pain (38-40). Eventually, they experience exhaustion, are unable to feel joy and feel depressed (41); their thinking is circumscribed and one-tracked, and they find it difficult to be creative. The ability to concentrate and remember things is reduced, and eventually the course changes into despair and depression. Initially, the depression is mild but deepens over time $(30,42)$.

It is important to systematically chart the effects of various placebos, because they have been shown to have an influence on experimental trials $(43,44)$ and in connection with treatment $(45,46)$. The pain-reducing effects of placebos have been obtained in several studies $(47,48)$. Given the assumption that placebo effects of expectations $(49,50)$ and the importance of attention $(51,52)$ are inherent in various pain-reducing treatments, it is important to control for these effects, as well as other potential effects such as worrying, anxiety (53), affectivity and optimism (54-58).

Given that the expectancy-placebo technique used in alcohol and drug experiments is basically impossible with flotationREST, Norlander et al (28) conducted an experiment including two conditions: one with a group of former drug addicts, who had used hallucinogenic drugs, and a matched group of 'ordinary' people; and another with a 'strict setting' (the experimenter wore a white coat, the walls were barren and the instructions to lie down in the tank were without comments) and a 'fantasy setting' (the experimenter wore a sweatshirt with a suggestive picture on it, there were fantasy pictures on the walls and there was a suggestive depiction of what could be expected while lying in the tank). Despite these manipulations, no significant differences were found between the conditions. The conclusion was that what happened in the tank was not affected much by either prior experiences or the setting and, consequently, that the flotation-REST technique is most likely not sensitive to placebo effects. What happens in flotationREST, as well as in chamber REST (ie, lying on a stretcher in a sound-and light-isolated room), though slightly less powerful
(59), appears to be the effect of sensory deprivation, not of expectation.

Previous studies (20) of pain reduction using flotationREST have not thoroughly addressed the attention-placebo problem, ie, examined the potential role of attention. However, in a recently completed study by Kjellgren et al (20), in which the participants in the control group and the flotation group received equal amounts of attention, the results suggested that attention-placebo is not a factor of importance in terms of the flotation-REST results. To further examine this issue, the patients of the present study were treated with flotation-REST for a period of six weeks, and attention was given in two conditions: for six weeks in conjunction with the tank visits, or for 12 weeks, including six weeks before the treatment and for six weeks in conjunction with the tank visits.

Patients with stress-related pain often, over time, develop problems that are diagnosed as burnout depression (29,33). In the present study, we explored whether there are differences between patients with or without burnout diagnoses with regard to attention.

To examine the potential effect of attention-placebo in pain treatment, it is important to find different ways of measuring perceived pain (20), because it could be that intense pain is affected by a particular treatment, whereas low-intensity pain is not. The more consistent the responses of the participants in terms of different measures of pain following treatment, the more reliable the measures in terms of assessing the patients' total pain experiences. Previous studies (20), in large part, only focused on the intensity of the pain. In the present study, several different aspects of pain assessment were used (eg, the breadth of the area of pain, the number of areas of pain and the different types of pain), with the purpose of providing a more all-encompassing picture of patients' pain problems, and how they are affected by attention as well as flotationREST.

\section{Participants}

\section{METHODS}

Thirty-two patients (25 women and seven men) were recruited from the waiting list at the Human Performance Laboratory at Karlstad University, Karlstad, Sweden. They had been diagnosed by a physician as having stress-related pain of a muscle tension type. They reported having had such pain for an average of $11.37 \pm 9.92$ years and $21.9 \%$ stated that they experienced the pain during the day and night, $43.8 \%$ daily, 25\% weekly, $6 \%$ monthly and $3.1 \%$ rarely. Among the patients, 16 of them had also received the diagnosis of burnout depression (including symptoms such as fatigue, less energy, problems with organizing daily life, problems with memory and processing new information, problems with sleep and feelings of low spiritedness, with the ailments not being relieved by rest). One-half of the 32 patients received special attention (see Design and Procedure) for a total of 12 weeks (high attention), while the other half received attention for only six weeks (normal attention). The average age of the patients was $48.46 \pm 9.51$ years. Statistical analyses using independent sample $t$ tests ( $5 \%$ level) yielded no significant age differences between groups regarding sex, burnout depression or attention $(\mathrm{P}>0.05)$.

\section{Design}

The study used a three-way split plot design in which treatment with the flotation tank, with assessments before and after the tank visit, constituted the within-subjects factor, and attention (ie, normal 
attention or high attention) and diagnosis (ie, nonburnout patients with stress-related pain or burnout patients with stressrelated pain) constituted the between-subjects factors. The variable attention was created by giving one-half of the patients attention for 12 weeks and the other half for only six weeks (see Procedure). The group with normal attention was comprised of nine patients without burnout depression and seven patients with depression, whereas the group with high attention was comprised of seven patients without burnout and nine patients with burnout depression. There were significantly more women than men, but they turned out to be quite evenly distributed across conditions, attention (three and four patients) and diagnosis (five and two patients). All participants, regardless of condition, were treated with flotation-REST for a seven-week period. The period consisted of two treatments per week for three weeks, followed by a week without treatment, then another three weeks of treatments. Thus, the participants received a total of 12 flotations during two periods of three weeks each.

\section{Measures}

Flotation tank: A flotation tank (Delfi, Varberg, Sweden) measuring $2700 \mathrm{~mm} \times 1500 \mathrm{~mm} \times 1300 \mathrm{~mm}$ was used. The depth of fluid (salt water) varied between $200 \mathrm{~mm}$ and $300 \mathrm{~mm}$. The flotation tank was insulated to maintain a constant air and water temperature and to reduce incoming light and noise. The water temperature was maintained at $34.7^{\circ} \mathrm{C}$ and was saturated with magnesium sulphate (density $1.3 \mathrm{~g} / \mathrm{cm}^{3}$ ). The tank was equipped with a horizontal entrance that was easy to open and close (from both the inside and the outside) by the subject. Between flotations, a hydrogen peroxide solution was poured in; then, the salt water was filtered and sterilized with ultraviolet light. The number and duration of treatments, ie, 12 treatments over a seven-week period (two three-week treatment periods with a nontreatment week in between), was based on similar procedures described in the literature and from the authors' experiences. The reason for having two three-week treatment periods was so that participating women could plan the timing of their flotation treatments from the incidence of each menstrual cycle.

Questionnaire 1: Before the treatment (ie, attention and floating), a questionnaire was provided that estimated each subject's selfassessed pain: intensity, areas and types, frequency, duration, onset and treatment, as well as experience or symptoms of other types of complaints. Each subject's own descriptions of 'most severe pain intensity' and 'normal pain intensity', respectively, were estimated on visual analogue scales (0 to 100). Additionally, information regarding alcohol consumption was collected.

Questionnaire 2: At a final meeting, after seven weeks of the experimental flotation procedure, the same questions were presented as in questionnaire 1 .

Pain area inventory: The pain area inventory (PAI), developed for use in the present study, consisted of two anatomical images of a human being, one frontal and one dorsal. The task of the participants was to indicate with a colour pen their areas of pain and colour them in. A transparent, plastic film was then placed over the coloured areas on both figures. Each figure was divided into 833 equal-sized squares (1666 total), and the number of coloured squares was calculated. The size of the square was $3 \mathrm{~mm} \times 4 \mathrm{~mm}$, and one square $\left(12 \mathrm{~mm}^{2}\right)$ corresponded with $0.06 \%$ of the total area of the two figures.

A correlation, computed with the aid of an interitem analysis, included all measures of pain (ie, PAI, the total number of pain types, the number of connected pain areas, most severe pain intensity, normal pain intensity and pain frequency) following treatment, indicated a high degree of consistency of the responses (standardized item alpha $=0.84)$. A multiple regression (entermethod) with PAI (ie, number of squares) as the criterion variable and the other pain measures as predictor variables yielded a significant correlation $(r=0.70, P=0.001)$. Test-retest reliability was examined using a group of pain patients $(n=34)$ who completed the PAI on two occasions, seven weeks apart $(\mathrm{r}=0.92, \mathrm{P}=0.01)$.

Stress and energy: The stress and energy (SE) instrument was a self-estimation instrument concerning individuals' energy and stress experiences (60). It consisted of two subscales that elucidated the mood levels of the subjects on the dimensions 'experienced stress' and 'experienced energy'. The response alternatives were arranged on six-grade scales, extending from 0 (not at all) to 5 (very much). The instrument has been validated by analyses from studies (60-62) focused on occupational burdens and pressures. The SE scale was constructed and based on an early and much used checklist, the Mood Adjective Checklist, constructed by Nowlis and Green (63), and modified further and translated into Swedish by Kjellberg and Bohlin (62). Kjellberg and Iwanowski (60) reduced the list to 12 adjectives in two dimensions. It is the most current version of the SE scale (with test-retest scores of 0.73 to 0.78 ) and was used in the present study. The test did not have a time limit.

Hospital anxiety depression scale: The hospital anxiety depression scale (HAD) scale is a rating scale used to measure the degree of anxiety and depression, and is referred to in various published articles. It was constructed by Zigmond and Snaith (64) for use with physically ill people. It has since been revised to be used as a rating scale for anxiety and depression. Its validity and reliability were examined by Hermann (65). The instrument consists of 14 statements with four response alternatives (ie, 0 through 3 ), ranging from positive to negative or vice versa, with seven statements regarding anxiety and seven regarding depression.

Life orientation test: The life orientation test (LOT) (66) consists of eight items plus four filler items. The task of each participant is to decide whether one is in agreement with each of the items described on a scale of 0 to 4 , where 0 indicates 'strongly disagree' and 4 indicates 'strongly agree'. The test measures dispositional optimism, defined in terms of generalized outcome expectancies. Parallel test reliability is reported at 0.76 and internal consistency at $0.76(66)$ and test-retest reliability is reported at 0.75 (67). LOT is also regarded as having an adequate level of convergent and discriminant validity (66), as demonstrated by correlation statistics and by using LISREL VI (SPSS, USA) ( $\mathrm{r}=0.64)$.

Positive affect and negative affect scales: The positive affect and negative affect scales (PANAS) instrument (68-71) assesses the degree of affect, both negative affect (NA) and positive affect (PA). The instrument consists of 10 adjectives for the NA dimension and 10 adjectives for the PA dimension. In the test manual (71), it is postulated that the adjectives describe feelings and mood. The participants were asked to estimate how they had been feeling during the last week. Response alternatives are presented on five degree scales ranging from 0 (not at all) to 5 (very much). The PANAS scale has been validated through studies focused on several different routinely used scales within psychopathology (72). Cronbach's alpha for PA was 0.73 and for NA was 0.76 in the present study.

\section{Procedure}

The participants were recruited from the waiting list for participation in the flotation-REST experiment at the Human Performance Laboratory, Karlstad University. They were originally referred by 
their physicians or had responded to announcements for individuals suffering from localized muscle tension pain in the neck and shoulder area, with or without temporal headache, associated with myofascial tender points or trigger points. At the same time, patients were recruited from the list to two experiments: a first experiment with 70 participants; and a second experiment (the present study) with a flotation-REST group consisting of 16 individuals. The two experiments overlapped.

For the present study, the high attention group was recruited by asking 20 patients, who had just completed participation in the control group (in the first experiment), whether they would be willing to continue immediately with a new experiment involving the flotation tank. This means that they were not asked at the same time but rather when their participation in the control group was to finish. They had not been told before the first experiment that they would have the option of receiving flotation therapy after the control sessions had ended. Asking 20 individuals seemed reasonable because estimates on power, based on earlier experiences, indicated that 15 individuals in each group would be sufficient to detect a treatment effect. All of the patients agreed to participate in a new experiment, but four of them cancelled due to lack of time immediately before the experiment or in the beginning of treatment. Thus, the group consisted of 16 participants. Given that they had already participated in a control group, they had regularly visited the laboratory and met the staff to the same extent as the flotation group (normal attention). On those occasions, they sat alone in a closed room, in an easy chair reading their own literature or literature provided for 45 min twice per week for three weeks; they then had one week with no treatment, followed by another three weeks with attention. In the new experiment, the participants immediately continued with the flotationREST treatment and with identical treatment intervals (ie, twice a week for three weeks, then one week without treatment, followed by a final three-week period), along with continued visits with the staff as before. The nature of attention (ie, associating with the staff) the group received was the same across the first and second set of 12 sessions, even though the activity alone in a closed room (ie, armchair- or flotation-REST) differed. Thus, this group received flotation treatment 12 times and attention on 24 occasions during a period of 12 weeks.

The other group (normal attention) had not had any previous contact with the laboratory but was randomly recruited straight from the patient waiting list as described. The procedure was complete when 16 people agreed to participate in the experiment and fulfilled the criteria for inclusion. Subsequently, two individuals dropped out, one for lack of time and the other due to his experience of being shut in the tank at the beginning of the flotationREST treatment. They were then replaced by two individuals randomly picked from the waiting list. All in all, this group also received 12 treatments during a period of six weeks, but attention only at the time of their 12 tank visits.

With regard to the second independent variable of the study, experience was already available, suggesting that approximately one-half of the patients with stress-related pain from muscular tension who seek treatment are also diagnosed with burnout depression. Thus, no further groupings of patients were carried out. Only in connection with the analyses was it found that the normal attention group consisted of seven patients with the diagnosis of burnout depression, whereas the groups with high attention consisted of nine patients with that diagnosis. These numbers were deemed sufficient for the statistical requirements of a threeway ANOVA with mixed design.
Both the high and normal attention group had to visit the laboratory physician and a pain specialist before the study, where they were informed about the project, screened for suitability through questionnaire 1, underwent a medical examination (which included blood pressure and heart rate) and a careful pain analysis, including palpation of muscle tone and a neurological examination. Among the exclusion criteria were pregnancy or breastfeeding, somatic problems or illnesses requiring other types of treatment, open wounds, manifest psychiatric symptoms, neurological disturbances, whiplash related disorders, manifest post-traumatic stress disorder, as well as regular treatment with heavy opiate analgesics and signs of anxiety/fear or discomfort being in a restricted environment.

During the interview, each participant's degree of anxietydepression was assessed using the HAD scale, whereupon the other personality tests and other psychological tests were completed. Every participant received a leaflet with patient-oriented information about flotation-REST, wherein (in addition to the purely practical details associated with treatment) they were also informed that driving was not recommended shortly after treatment (due to increased risk of transient tiredness). During this initial contact, each subject was shown around the floatarium. The information was restricted (no mentioning of possible changes in consciousness), and the participants were only informed that most people experience the floating as relaxing.

All participants were given flotation treatment during the forthcoming three periods (with two visits per week); each floating session was $45 \mathrm{~min}$ in duration. After that, the participants had one week without treatment, followed by another three-week period of treatment. The experimenters at the flotation site were ignorant of the group identity of each participant and, thus, for all purposes, experimentally blind. A procedure consisting of a 'first come, first assigned' method was applied. When the participant was using the flotation tank at the very first session, the patient was informed of the flotation technique, shown the bathroom and shower, and thoroughly reminded of their freedom to terminate the session if necessary. Following instructions to visit the bathroom, shower, insert earplugs and relax, each participant was allowed to immerse in the water of the tank and close the lid unaided. Treatment was terminated after $45 \mathrm{~min}$, when the experimenter gently knocked on the exterior of the tank. Three days (or $72 \mathrm{~h}$ ) after the final treatment session, participants attended a final consultation and follow-up discussion, at which time they completed questionnaire 2 and the psychological tests. All of the patients described completed the whole course of treatment (ie, 12 sessions over six weeks)

\section{RESULTS}

\section{Pain measurements}

Statistical analyses were carried out using three-way split plot ANOVA with treatment as the within-subjects factor and attention and diagnosis as between-subjects factors, and with the number of different ways of measuring subjective pain (ie, PAI, number of different types of pain, number of comprehensive pain areas, most severe pain intensity, normal pain intensity and pain frequency) as the dependent variables. For means and SDs, see Table 1 .

\section{PAI}

The analyses yielded a significant difference for treatment $\left(\mathrm{F}[1,28]=18.42, \mathrm{P}<0.001, \mathrm{Eta}^{2}=0.40\right.$, power=0.99), and a 
TABLE 1

Pain measurement scores before (1) and after (2) treatment in regard to attention and diagnosis

\begin{tabular}{|c|c|c|c|c|c|}
\hline & \multicolumn{2}{|c|}{ Normal attention } & \multicolumn{2}{|c|}{ High attention } & \multirow{2}{*}{$\begin{array}{c}\text { Treatment } \\
\text { Before and after }\end{array}$} \\
\hline & Nondepressed & Depressed & Nondepressed & Depressed & \\
\hline PAI 1 & $84.78(83.36)$ & $224.14(196.23)$ & $126.14(93.86)$ & $188.79(185.00)$ & $153.56(151.03)$ \\
\hline PAI 2 & $36.22(25.79)$ & $88.86(113.90)$ & $50.86(62.16)$ & $30.22(41.08)$ & $49.25(65.94)^{\star}$ \\
\hline Types 2 & $2.33(1.22)$ & $1.71(1.25)$ & $1.86(1.07)$ & $1.56(1.33)$ & $1.88(1.21)^{*}$ \\
\hline Areas ${ }^{\ddagger} 1$ & $6.33(2.65)$ & $10.14(11.78)$ & $4.14(3.02)$ & $5.78(3.67)$ & $6.53(6.19)$ \\
\hline Areas 2 & $4.11(3.10)$ & $7.29(10.70)$ & $2.57(2.15)$ & $2.00(3.20)$ & $3.88(5.68)^{*}$ \\
\hline Severest 2 & $70.33(14.85)^{\star \star}$ & $48.29(26.46)$ & $33.29(23.73)^{\star \star}$ & $53.67(27.77)$ & $52.72(26.09)^{*}$ \\
\hline Normal"T 1 & $41.33(16.93)$ & $37.86(23.25)$ & $44.71(13.11)$ & $33.00(22.11)$ & 38.97 (18.91) \\
\hline Normal 2 & $37.33(14.75)$ & $28.71(20.96)$ & $16.57(19.34)$ & $25.00(26.05)$ & $27.44(21.12)^{*}$ \\
\hline Frequency ${ }^{\dagger \dagger} 1$ & $4.11(0.60)$ & $3.71(0.76)$ & $4.29(0.76)$ & $3.00(1.22)$ & $3.75(0.98)$ \\
\hline Frequency 2 & $3.89(0.78)$ & $3.14(1.46)$ & $2.86(1.68)$ & $2.78(1.48)$ & $3.19(1.38)^{\star}$ \\
\hline
\end{tabular}

Data are presented as mean $(S D)$. *Significant difference $(P<0.05)$ in the after condition; ** Significant difference for attention by diagnosis $(P<0.05)$ in the nondepressed and after conditions; ${ }^{\dagger}$ Number of different types of pain; $¥$ Number of comprehensive pain areas; $\$$ Severest pain intensity; ${ }^{\top}$ Normal pain intensity; ${ }^{\dagger+}$ Pain frequency. PAI Pain area inventory

descriptive analysis showed that pain assessed with the PAI was reduced from 153.56 squares ( $\mathrm{SD}=151.03$ squares) to 49.25 squares $(\mathrm{SD}=65.94$ squares $)$ during the period of treatment. There were no other significant effects $(\mathrm{P}>0.05)$.

Number of different types of pain: The analyses yielded a significant difference for treatment $(\mathrm{F}[1,28]=16.25, \mathrm{P}<0.001$, $\mathrm{Eta}^{2}=0.37$, power $=0.97$ ), and a descriptive analysis showed that the number of types of pain was reduced from 2.88 $(\mathrm{SD}=1.26)$ to $1.88(\mathrm{SD}=1.21)$ during the treatment period. There were no other significant effects $(\mathrm{P}>0.05)$. Additional analyses suggested that headaches, jaw, neck and, in particular, back pain diminished.

Number of comprehensive pain areas: The analyses yielded a significant effect for treatment $(\mathrm{F}[1,28]=14.63, \mathrm{P}=0.001$, $\mathrm{Eta}^{2}=0.34$, power $=0.96$ ), and a descriptive analysis showed that the number of comprehensive pain areas diminished from $6.53(\mathrm{SD}=6.19)$ to $3.88(\mathrm{SD}=5.68)$ during the treatment period. There were no other significant effects $(\mathrm{P}>0.05)$.

Most severe pain intensity: The analyses yielded a significant difference for treatment $\left(\mathrm{F}[1,28]=10.48, \mathrm{P}=0.003\right.$, $\mathrm{Eta}^{2}=0.27$, power $=0.88$ ), and a descriptive analysis showed that the most severe pain intensity was reduced from $69.72(\mathrm{SD}=24.24)$ to $52.72(\mathrm{SD}=26.09)$ during the treatment period. In addition, there was a significant attention by diagnosis interaction effect $\left(\mathrm{F}[1,28]=5.46, \mathrm{P}=0.027, \mathrm{Eta}^{2}=0.16\right.$, power $\left.=0.62\right)$, suggesting that patients without burnout depression and who received high attention exhibited the most extensive pain reduction of all, whereas participants without burnout and who received normal attention displayed the smallest amount of pain reduction. Patients with burnout depression displayed the same amount of pain reduction, irrespective of degree of attention. There were no other significant effects $(\mathrm{P}>0.05)$.

Normal pain intensity: The analyses yielded a significant difference for treatment $\left(\mathrm{F}[1,28]=11.67, \mathrm{P}=0.002, \mathrm{Eta}^{2}=0.29\right.$, power $=0.91$ ), and a descriptive analysis showed that normal pain intensity diminished from $38.97(\mathrm{SD}=18.91)$ to 27.44 $(S D=21.12)$ during the treatment period. There were no other significant effects $(\mathrm{P}>0.05)$.

Pain frequency: The analyses yielded a significant difference for treatment $\left(\mathrm{F}[1,28]=9.02, \mathrm{P}=0.006, \mathrm{Eta}^{2}=0.24\right.$, power $\left.=0.83\right)$, and a descriptive analysis showed that the pain frequency diminished from 'daily' (mean=3.74, SD=0.98) to 'weekly' (mean $=3.19, \mathrm{SD}=21.12$ ) during the treatment period. There were no other significant effects $(\mathrm{P}>0.05)$.

\section{Blood pressure and heart rate}

Statistical analyses were conducted using three-way split plot ANOVA with treatment as the within-subjects factor and attention and diagnosis as between-subjects factors, and with blood pressure $(\mathrm{mmHg})$ and heart rate as dependent variables. For means and SDs, see Table 2.

Systolic blood pressure: The analyses yielded no significant effects for treatment, attention, diagnosis or their interactions $(\mathrm{P}>0.05)$.

Diastolic blood pressure: The analyses yielded a significant difference for treatment $\left(\mathrm{F}[1,28]=5.85, \mathrm{P}=0.022, \mathrm{Eta}^{2}=0.17\right.$, power $=0.65)$, and a descriptive analysis showed that the diastolic blood pressure diminished from $83.25 \mathrm{mmHg}(\mathrm{SD}=10.47)$ to $80.03 \mathrm{mmHg}(\mathrm{SD}=8.72)$ during the treatment period. There were no other significant effects $(\mathrm{P}>0.05)$.

Heart rate: The analyses did not yield any significant effects for treatment, attention, diagnosis or any interactions $(\mathrm{P}>0.05)$.

\section{Medication and alcohol}

First, a $\chi^{2}$ test was performed to find out how many participants used medication before or after the treatment. Then, statistical analyses with three-way split plot ANOVA were performed with treatment as the within-subjects factor, with attention and diagnosis as between-subjects factors, and with alcohol and medicine consumption (ie, the number of types of medication) as the dependent variables. For means and SDs, see Table 3.

Consumption or nonconsumption of medication: Before treatment, 21 patients reported taking medication regularly and 11 did not; following treatment, 16 patients reported taking medication regularly and 15 did not. This change was shown to be significant (Fisher's exact test, $\mathrm{P}=0.001$ ).

Number of types of medication: The analyses yielded a significant difference for treatment $(\mathrm{F}[1,28]=15.99, \mathrm{P}<0.001$, 
TABLE 2

Mean blood pressure $(\mathrm{mmHg})$ and pulse rate (beats/mean), before (1) and after (2) treatment in regard to attention and diagnosis

\begin{tabular}{|c|c|c|c|c|c|}
\hline & \multicolumn{2}{|c|}{ Normal attention } & \multicolumn{2}{|c|}{ High attention } & \multirow{2}{*}{$\begin{array}{c}\text { Treatment } \\
\text { Before and after }\end{array}$} \\
\hline & Nondepressed & Depressed & Nondepressed & Depressed & \\
\hline Systolic 1 & $135.00(23.72)$ & $129.43(9.20)$ & $142.57(13.09)$ & $130.33(14.45)$ & $134.13(16.56)$ \\
\hline Systolic 2 & $135.33(20.96)$ & $126.57(11.53)$ & $135.86(12.24)$ & $124.78(11.24)$ & $130.56(15.07)$ \\
\hline Diastolic 1 & 85.89 (16.07) & $78.14(4.88)$ & $81.86(6.31)$ & 85.67 (8.92) & $83.25(10.47)$ \\
\hline Diastolic 2 & $83.33(13.44)$ & $76.14(6.69)$ & $79.29(4.42)$ & $80.33(6.30)$ & $80.03(8.72)^{*}$ \\
\hline Pulse 1 & $71.44(8.92)$ & $72.57(7.30)$ & $68.00(6.08)$ & $70.11(10.62)$ & $70.56(8.35)$ \\
\hline Pulse 2 & $74.24(10.74)$ & $69.00(4.69)$ & $69.86(8.67)$ & $66.89(7.49)$ & $69.94(8.32)$ \\
\hline
\end{tabular}

Data are presented as mean $(S D)$. *Significant difference $(P<0.05)$ in the after condition

TABLE 3

Scores for for number of different kinds of medication, number of analgesics and alcohol consumption before (1) and after (2) treatment in regard to attention and diagnosis

\begin{tabular}{|c|c|c|c|c|c|}
\hline & \multicolumn{2}{|c|}{ Normal attention } & \multicolumn{2}{|c|}{ High attention } & \multirow{2}{*}{$\begin{array}{c}\text { Treatment } \\
\text { Before and after }\end{array}$} \\
\hline & Nondepressed & Depressed & Nondepressed & Depressed & \\
\hline Drugs 1 & $1.56(1.42)$ & $1.71(1.70)$ & $2.29(2.14)$ & $1.11(1.36)$ & $1.63(1.62)$ \\
\hline Drugs 2 & $1.00(0.87)$ & $0.71(1.11)$ & $0.86(1.07)$ & $0.78(1.09)$ & $0.84(0.99)^{*}$ \\
\hline Analgesics 1 & $1.00(0.87)$ & $1.00(1.16)$ & $0.71(1.25)$ & $0.22(0.44)$ & $0.72(0.96)$ \\
\hline Analgesics 2 & $0.78(0.83)$ & $0.14(0.38)$ & $0.57(1.13)$ & $0.00(0.00)$ & $0.43(0.79)^{\star}$ \\
\hline Alcohol 1 & $288.89(209.85)$ & $137.71(140.82)^{\star *}$ & 285.71 (179.99) & $180.00(142.54)^{\star \star}$ & $224.50(176.19)$ \\
\hline Alcohol 2 & $220.56(133.26)$ & $104.29(108.55)^{\star \star}$ & $260.00(161.74)$ & $121.11(101.80)^{\star \star}$ & $175.78(137.13)^{*}$ \\
\hline
\end{tabular}

Data are presented as mean $(S D)$. * Significant difference $(P<0.05)$ in the after condition; ** Significant difference $(P<0.05)$ in the depressed condition

$\mathrm{Eta}^{2}=0.36$, power $=0.97$ ), and a descriptive analysis showed that the participants reported reducing the number of medications from $1.63(\mathrm{SD}=1.62)$ to $0.84(\mathrm{SD}=0.99)$ during the treatment period. There were no other significant effects $(\mathrm{P}>0.05)$. Number of different types of pain medication: The analyses yielded a significant effect for treatment $(F[1,24]=6.43$, $\mathrm{P}=0.018, \mathrm{Eta}^{2}=0.21$, power $\left.=0.68\right)$, and a descriptive analysis showed that the participants reported reducing the number of types of pain medication from $0.72(\mathrm{SD}=0.96)$ to 0.43 $(\mathrm{SD}=0.79)$ during the treatment period. There were no other significant effects $(\mathrm{P}>0.05)$.

Alcohol intake: The analysis yielded a significant effect for treatment $\left(\mathrm{F}[1,28]=5.03, \mathrm{P}=0.033, \mathrm{Eta}^{2}=0.15\right.$, power=0.58), and a descriptive analysis showed that the participants reported reducing their alcohol intake per month (calculated as millimetres $100 \%$ alcohol) from $224.50 \mathrm{~mm}(\mathrm{SD}=176.19)$ to $175.78 \mathrm{~mm}(\mathrm{SD}=137.13)$ during the treatment period. In addition, there was a significant difference for diagnosis $\left(\mathrm{F}[1,28]=6.63, \mathrm{P}=0.016, \mathrm{Eta}^{2}=0.19\right.$, power=0.70), and a descriptive analysis showed that the participants without a diagnosis of burnout had a greater intake (mean=262.66 mm, $\mathrm{SD}=166.77 \mathrm{~mm}$ ) than those who did have a diagnosis of burnout (mean=137.63 mm, SD=120.12 mm).

\section{Personality variables}

Statistical analyses were carried out using three-way split plot ANOVA with treatment as the within-subjects factor, attention and diagnosis as between-subjects factors, and the psychological variables derived from four personality tests as the dependent variables, ie, SE, HAD scale, LOT and PANAS. For means and SDs, see Table 4.

Stress: The analyses yielded a significant difference for treatment $\left(\mathrm{F}[1,28]=37.92, \mathrm{P}<0.001, \mathrm{Eta}^{2}=0.58\right.$, power $\left.>0.99\right)$, and a descriptive analysis showed that stress was reduced from 2.24 $(\mathrm{SD}=0.97)$ to $1.36(\mathrm{SD}=0.78)$ during the treatment period. There were no other significant effects $(\mathrm{P}>0.05)$.

Energy: The analyses yielded a significant effect for attention $\left(\mathrm{F}[1,28]=5.01, \mathrm{P}=0.033, \mathrm{Eta}^{2}=0.15\right.$, power $\left.=0.58\right)$, whereas those who received high attention displayed more combined energy, irrespective of treatment (mean $=3.35, \mathrm{SD}=0.99)$, compared with those who received normal attention (mean $=2.86$, $\mathrm{SD}=0.82$ ). In addition, there was a significant difference for diagnosis $\left(\mathrm{F}[1,28]=6.76, \mathrm{P}=0.015, \mathrm{Eta}^{2}=0.19\right.$, power=0.71), in that participants who did not have a disgnosis of burnout displayed more combined energy (mean $=3.40, \mathrm{SD}=0.86)$ than those who had a diagnosis of burnout (mean=2.81, $\mathrm{SD}=0.90)$. There were no other significant effects $(\mathrm{P}>0.05)$.

Anxiety: The analyses yielded a significant difference for treatment $\left(\mathrm{F}[1,28]=46.20, \mathrm{P}<0.001, \mathrm{Eta}^{2}=0.62\right.$, power $\left.>0.99\right)$, and a descriptive analysis showed that the anxiety was reduced from $7.75(\mathrm{SD}=3.46)$ to $5.22(\mathrm{SD}=3.25)$ during the treatment period. There were no other significant effects $(\mathrm{P}>0.05)$.

Depression: The analyses yielded a significant difference for treatment $\left(\mathrm{F}[1,28]=19.16, \mathrm{P}<0.001, \mathrm{Eta}^{2}=0.41\right.$, power=0.99), and a descriptive analysis showed that depression diminished from $5.28(\mathrm{SD}=4.19)$ to $3.16(\mathrm{SD}=3.12)$ during the treatment period. In addition, there was a significant difference for diagnosis $\left(\mathrm{F}[1,28]=20.30, \mathrm{P}<0.001, \mathrm{Eta}^{2}=0.42\right.$, power $\left.>0.99\right)$, and a descriptive analysis showed that the participants who did not have the diagnosis of burnout depression displayed lower levels of depression (mean=2.34, $\mathrm{SD}=2.16)$ than those who did have the diagnosis (mean=6.09, $\mathrm{SD}=3.92)$. There were no other significant effects $(\mathrm{P}>0.05)$.

Optimism: The analyses yielded a significant difference for treatment $\left(\mathrm{F}[1,28]=17.06, \mathrm{P}<0.001, \mathrm{Eta}^{2}=0.38\right.$, power=0.98), and a descriptive analysis indicated that optimism increased 


\section{TABLE 4}

Mean scores for personality variables before (1) and after (2) treatment in regard to attention and diagnosis

\begin{tabular}{|c|c|c|c|c|c|}
\hline & \multicolumn{2}{|c|}{ Normal attention } & \multicolumn{2}{|c|}{ High attention } & \multirow{2}{*}{$\begin{array}{c}\text { Treatment } \\
\text { Before and after }\end{array}$} \\
\hline & Nondepressed & Depressed & Nondepressed & Depressed & \\
\hline Stress 1 & $2.11(0.88)$ & $2.81(0.91)$ & $2.02(1.17)$ & $2.09(0.91)$ & $2.24(0.97)$ \\
\hline Stress 2 & $1.22(0.76)$ & $1.69(1.17)$ & $1.07(0.36)$ & $1.46(0.70)$ & $1.36(0.78)^{*}$ \\
\hline Energy 2 & $3.02(0.84)$ & $2.38(0.47)^{\dagger}$ & $3.93(0.58)^{\ddagger}$ & $2.74(0.96)^{\dagger \ddagger}$ & $3.00(0.91)$ \\
\hline Anxiety 1 & $7.00(4.09)$ & $10.14(3.24)$ & $7.14(2.48)$ & $7.11(3.30)$ & $7.75(3.46)$ \\
\hline Depression 2 & $2.44(2.40)$ & $6.43(3.60)^{\dagger}$ & $0.71(0.49)$ & $3.22(2.64)^{\dagger}$ & $3.16(3.12)^{*}$ \\
\hline Optimism 1 & $20.89(2.76)$ & $14.71(3.25)^{\dagger}$ & $24.86(3.81)$ & $22.89(4.78)^{\dagger}$ & $20.97(5.10)$ \\
\hline Optimism 2 & $23.33(4.21)$ & $18.71(5.41)^{\dagger}$ & $26.14(2.41)^{\S}$ & $23.33(5.20)^{\dagger \S}$ & $22.94(4.82)^{\star}$ \\
\hline PA 1 & $34.89(7.75)$ & $27.57(6.95)^{\dagger}$ & $37.14(4.30)$ & $30.78(11.58)^{\dagger}$ & $32.63(8.71)$ \\
\hline PA 2 & $37.89(6.57)$ & $32.43(6.02)^{\dagger}$ & $40.86(5.49)$ & $32.33(5.20)^{\dagger}$ & $35.78(6.64)^{\star}$ \\
\hline NA 1 & $16.22(3.19)$ & $25.43(6.93)^{\dagger}$ & $19.00(5.35)$ & $22.44(10.50)^{\dagger}$ & $20.59(7.64)$ \\
\hline
\end{tabular}

Data are presented as mean $(S D)$. * Significant difference $(P<0.05)$ in the after condition; + Significant difference $(P<0.05)$ in the depressed condition; $¥$ Significant difference $(P<0.05)$ in the high-attention condition; §Significant difference for attention by treatment $(P<0.05)$ in the high-attention and after conditions. NA Negative affectivity; PA Positive affectivity

from $20.97(\mathrm{SD}=5.10)$ to $22.94(\mathrm{SD}=4.82)$ during the treatment period. In addition, there was a significant difference for diagnosis $\left(\mathrm{F}[1,28]=8.29, \mathrm{P}=0.008, \mathrm{Eta}^{2}=0.23\right.$, power=0.79), and a descriptive analysis showed that the participants without burnout depression exhibited greater optimism (mean $=23.59$, $\mathrm{SD}=3.73$ ) than those with the diagnosis of burnout depression (mean=20.31, SD=5.58). Finally, there was a significant treatment by attention interaction $(\mathrm{F}[1,28]=5.68, \mathrm{P}=0.024$, $\mathrm{Eta}^{2}=0.17$, power $=0.63$ ), which indicated that the participants who received high attention exhibited a smaller increase in optimism than those participants who received normal attention. The latter group showed a greater increase in optimism. There were no other significant effects $(\mathrm{P}>0.05)$.

PA: The analyses yielded a significant difference for treatment $\left(\mathrm{F}[1,28]=5.39, \mathrm{P}=0.028, \mathrm{Eta}^{2}=0.16\right.$, power=0.61), and $\mathrm{a}$ descriptive analysis showed that PA increased from 32.63 $(\mathrm{SD}=8.71)$ to $35.78(\mathrm{SD}=6.64)$ during the treatment period. In addition, there was a significant difference for diagnosis $\left(\mathrm{F}[1,28]=10.38, \mathrm{P}=0.003, \mathrm{Eta}^{2}=0.27\right.$, power=0.88), and $\mathrm{a}$ descriptive analysis indicated that the participants without the diagnosis of burnout depression exhibited a greater degree of PA (mean=37.53, $\mathrm{SD}=6.25)$ than did those with the diagnosis of burnout depression $($ mean $=30.88, \mathrm{SD}=7.53)$. There were no other significant effects $(\mathrm{P}>0.05)$.

NA: The analyses revealed a significant effect for treatment $\left(\mathrm{F}[1,28]=5.78, \mathrm{P}=0.023, \mathrm{Eta}^{2}=0.17\right.$, power=0.64), and a descriptive analysis showed that NA diminished from $20.59(\mathrm{SD}=7.64)$ to $17.44(\mathrm{SD}=8.82)$ during the treatment period. In addition, there was a significant difference for diagnosis $(F[1,18]=5.92$, $\mathrm{P}=0.022, \mathrm{Eta}^{2}=0.17$, power=0.65), and a descriptive analysis showed that the participants without burnout depression displayed less NA (mean=16.06, $\mathrm{SD}=4.57$ ) than those with the diagnosis of burnout depression $($ mean $=21.97, \mathrm{SD}=10.00)$. There were no other significant effects $(\mathrm{P}>0.05)$.

\section{DISCUSSION}

The purpose of the study was to examine the effect of attentionplacebo on the treatment results of flotation tank therapy. Many positive effects were evident for the patients, but these effects were not affected by the level of attention-placebo. These results are in line with those of an earlier study (28), in which it was revealed that attention-expectancy had negligible or no effect on flotation tank therapy. Thus, it is suggested that the excellent treatment results of flotation tank therapy, such as reduced perceived stress and pain, are primarily transmitted by physiological, hormonal and neurochemical effect, as a direct consequence of the RR and sensory deprivation.

It is already known that flotation tank therapy has a good effect on pain related to muscle tension $(20,24,25,73)$. These studies, however, did not control for the possible effect of attention-placebo by giving the participants in both the control group and the experimental group the same amount of attention. Furthermore, these studies used a more general approach and focused on pain-reducing effects in that the pain intensity diminished. To more confidently assess the effect of attention-placebo, a series of additional aspects of pain were examined. Most severe pain intensity and normal pain intensity, as well as aspects of clinical relevance to pain problems (such as measures of PAI), the number of different types of pain, the number of comprehensive pain areas and pain frequency were assesed. These aspects, in addition to pain intensity, are of major relevance to the patient's perception of pain. We were able to show that there was a significant, beneficial reduction of all of these aspects as a result of the flotation tank therapy and that this reduction of pain appears to be independent of the level of attention-placebo. It was shown that among the 32 patients, seven (22\%) became pain free, 18 (56\%) improved, six $(19 \%)$ experienced no change and, finally, one (3\%) worsened, as measured by the PAI ( \pm 20 squares).

To examine whether there would be any differences between patients who were diagnosed with burnout depression and those who had no such diagnosis, this dimension was included in the study. It was shown that the patients without the burnout diagnosis and who received high attention displayed the greatest reduction of 'the most severe pain intensity' of all patients. Patients who were diagnosed with burnout depression, on the other hand, exhibited the same amount of pain reduction, irrespective of level of attention. 
No other significant effects related to attention and the presences of burnout depression were obtained. The fact that the various measures of pain following treatment were highly intercorrelated (standardized item alpha $=0.84$ ), and high consistency of the patients' responses, strengthens the notion that the treatment, not the patient category or the presence of attentionplacebo, was the determining factor. Of the 16 patients with the diagnosis of burnout depression, 13 individuals reported either improvement or freedom from pain on the PAI as a result of the flotation tank therapy, whereas 12 of those without the diagnosis exhibited similar improvement.

Because pain may be viewed as a subjective experience, including a strong emotional (affective) component, factors such as stress load and personal factors have been shown to modulate the extent and amount of pain experience to a greater or lesser degree $(39,45,74-77)$. This notion makes it relevant to examine whether attention-placebo affects such factors in connection with flotation tank therapy. In the current study, a significant reduction of anxiety level, level of depression, perceived stress and NA were observed during the period of treatment, along with an increase of optimism, energy and PA. With the exception of the result that those patients who received high attention also displayed a smaller increase in optimism, no effect of attention-placebo on these variables was found, a finding that further underlines the notion that it is the RR, induced by flotation-REST, that determine these positive changes.

Five patients reported giving up a regular intake of medication, and the total intake of medication appeared to have diminished. Furthermore, the alcohol intake of the patients diminished significantly during the period of treatment. These results are in line with previous observations (9) suggesting that the intake of psychoactive drugs and alcohol is frequently spontaneously reduced over time when the RR is induced. The fact that diastolic blood pressure was lowered following treatment could also be an indication that the RR was induced.

The study did have some limitations. It could be argued that the high attention group had more experience with the

\section{REFERENCES}

1. Smith JC. Understanding Stress and Coping. New York: Macmillan Co, 1993.

2. Sandlund ES, Norlander T. The effects of Thai Chi Chuan relaxation and exercise on stress responses and well-being: An overview of research. Int J Stress Manage 2000; 7:139-49.

3. Norlander T, Sandholm C, Anfelt O. The physioacoustic method and the creative process. Percept Mot Skills 1998;86:1091-6.

4. Norlander T. [Alcohol and the Creative Process. Frameworks of Influence by Alcohol upon Creative Performance.] Orebro: Tryckverkstan, 1997.

5. Benson H. The Relaxation Response. New York: Morrow, 1975.

6. Esch T, Fricchione L, Stefano GB. The therapeutic use of the relaxation response in stress-related diseases. Med Sci Monit 2003;9:RA23-34.

7. Bleich HL, Boro ES. Systematic hypertension and the relaxation response. N Engl J Med 1977;296:1152-6.

8. Hoffman JW, Benson H, Arns PA, et al. Reduced sympathetic nervous system responsivity associated with the relaxation response. Science 1982;215:190-2.

9. Setterlind S. [From Hypnosis and Suggestion to Relaxation and Meditation. A Research Review.] Orebro: Welins, 1990.

10. Ben-Menachem M. [Relaxation. A Literature Survey and an Attempt to Build a New Model. School Psychological Therapy Research Program.] Goteborg: Gothenburg School Administration, 1977.

11. Borrie RA. Bridging the gap. In: Barabasz A, Barabasz M, eds. Clinical and Experimental Restricted Environmental Stimulation. New York: Springer-Verlag, 1993:21-7. setting and may, therefore, have had a different set of expectancies about treatment efficacy. It is possible that there are some differences in regard to expectancy, but another study (28) strongly indicated that flotation-REST is not particularly sensitive to expectancy-placebo. The most important component concerning attention in the flotation setting is probably the interaction with the staff at the laboratory. All participants, regardless of experiment and experimental group, encounter a nurse at the reception desk directly after arriving at the laboratory. The nurse follows the participant to an interview room and then to one of several treatment rooms (eg, flotation-REST, chamber REST, control and meditation). After the treatment, the patient is taken back to the interview room and is followed to the entrance. There are no interactions with other patients and everyone gets the same amount of attention regardless of condition.

All in all, the results suggest that flotation tank therapy is an effective and noninvasive method for the treatment of stress-related pain, and that the method is not affected more by a placebo than by other methods currently used in pain treatment. The treatment of both burnout depression and pain related to muscle tension constitutes a major challenge for the patient as well as the care provider, an area in which great gains can be made if the treatment is effective. An important aspect of such treatment is to find methods that involve rest and recovery, as well, an increased ability to experience happiness and hope. Flotation tank therapy may constitute an integral part of such treatment.

ACKNOWLEDGEMENT: The present study was approved by the Ethical Board on Experimentation on Human Subjects (Forskningsetikkommitten) at Orebro Academic Hospital, Orebro, Sweden.

FUNDING: The present study was supported by grants from the County Council (Landstinget) in Varmland, Sweden and from the Centre for Clinical Research, Karlstad, Sweden.

12. Suedfeld P. The restricted environmental stimulation technique in the modification of addictive behaviors: Through the centuries to frontiers for the eighties. Psychol Addict Behav 1983;2:231-7.

13. Mahoney MJ. Applications of flotation REST in personal development. In: Turner JW Jr, Fine TH, eds. Restricted Environmental Stimulation. Toledo: IRIS Publications, 1990:174-80.

14. Schulz P, Kaspar CH. Neuroendocrine and psychological effects of restricted environmental stimulation technique in a flotation tank. Biol Psychol 1994;37:161-75.

15. Forgays DG, Forgays DK. Creativity enhancement through flotation isolation. J Environ Psychol 1992;12:329-35.

16. Suedfeld P, Metcalfe J, Bluck S. Enhancement of scientific creativity by flotation REST (restricted environmental stimulation technique). J Environ Psychol 1987;7:219-31.

17. Norlander T, Bergman H, Archer T. Effects of flotation REST on creative problem solving and originality. J Environ Psychol 1998;18:399-408.

18. Sandlund ES, Linnarud M, Norlander T. Effects of stress versus flotation- REST relaxation on creativity and literacy skills in advanced English as a second language (ESL) composition. Int J Lang Commun Disord 2001;15:95-113.

19. Ballard E. REST in the treatment of persistent psycho physiological insomnia. In: Barabasz A, Barabasz M, eds. Clinical and Experimenta Restricted Environmental Stimulation. New York: Springer-Verlag, 1993:187-203

20. Kjellgren A, Sundequist U, Norlander T, Archer T. Effects of flotationREST on muscle tension pain. Pain Res Manag 2001;6:181-9. 
21. Fine TH, Turner JW Jr. The effect of brief restricted environmental stimulation therapy in the treatment of essential hypertension. Behav Res Ther 1982;20:567-70.

22. Suedfeld P, Borrie RA: Therapeutic Application of Chamber and Floatation Restricted Environmental Stimulation Therapy (REST) Vancouver: University of British Columbia, Department of Psychology, 1995.

23. Turner JW Jr, Fine TH. REST-assisted relaxation and chronic pain. The 23rd International Congress of Psychology. Acapulco, September 3, 1984.

24. Mereday C, Lehmann C, Borrie R. Flotation for the management of rheumatoid arthritis. In: Suedfeld P, Turner JW Jr, Fine TH, eds. Restricted Environmental Stimulation: Research and Commentary. New York: Springer-Verlag, 1990:169-73.

25. Wallbaum AB, Rzewnicki R, Steele H, Suedfeld P. Progressive muscle relaxation and restricted environmental stimulation therapy for chronic tension headache: A pilot study. Int J Psychosom 1991;38:33-9.

26. Norlander T, Bergman H, Archer T. Primary process in competitive archery performance: Effects of flotation REST. J Appl Sports Psychol 1999;11:194-209.

27. Jessen WE. In-tank floatation therapy. In: Turner JW Jr, Fine TH, eds. Restricted Environmental Stimulation. Toledo: IRIS Publications, 1990:152-7.

28. Norlander T, Kjellgren A, Archer T. The experience of flotation-REST as a function of setting and previous experience of altered states of consciousness. Imagination, Cognition and Personality 2001;20:161-78.

29. Johannisson K. [When insufficiency gets a new name.] In: Ekman R, Arntez B, eds. [Stress: The Molecules, the Individual, the Organization and the Society.] Stockholm: Liber, 2002:13-28.

30. Levi L. [Stress - a review. International and public health perspectives.] In: Ekman R, Arntez B, eds. [Stress: The molecules, the individual, the organization and the society.] Stockholm: Liber, 2002;44-61.

31. Turner JH. On the Origins of Human Emotions. Stanford: Stanford University Press, 2000.

32. Akerstedt T. [We need our sleep!] Lakartidningen 2002;99:150-2.

33. Asberg M, Nygren A, Rylander, G, Rydmark I. [Stress and Pain.] In: Ekman R, Arntez B, eds. [Stress: The Molecules, the Individual, the Organization and the Society.] Stockholm: Liber, 2002:224-32.

34. Ekman R, Arntez B, eds. [Stress: The Molecules, the Individual, the Organization and the Society.] Stockholm: Liber, 2002.

35. Maslach C, Schaufeli WB, Leiter MP. Job burnout. Annu Rev Psychol 2001;52;397-422.

36. Roost M, Nilsson P. [Sleep disorders - a public health problem.] Lakartidningen 2002;99:154-7.

37. Akerstedt T, Kecklund, G. [Sleep and recovery.] In: Ekman R, Arntez B, eds. [Stress: The Molecules, the Individual, the Organization and the Society.] Stockholm: Liber, 2002:264-71.

38. Nisell R, Lundeberg T. [Pain and inflammation.] Sodertalje: Syntex Nordica, 1993.

39. Skevington SM. Psychology of pain. Chichester: John Wiley \& Sons, 1995.

40. Sorensen J, Bengtsson A, Backman E, Henriksson KG, Bengtsson M. Pain analysis in patients with fibromyalgia. Effects of intravenous morphine, lidocaine, and ketamine. Scand J Rheumatol 1995;24:360-5.

41 Sjostrom B. [Research on Persistent Pain. Nursing as an Academic Discipline in Research, Training, and Primary Care.] Stockholm: Svensk sjukskoterskeforening, 2002.

42. Gallagher RM, Verma S, Mossey J. Chronic pain. Sources of late-life pain and risk factors for disability. Geriatrics 2000;55:40-4,47.

43. Baker SL, Kirch I. Hypnotic and placebo analgesia: Order effects and the placebo label. Contemp Hypn 1993;10:117-26.

44. Montgomery GH. Mechanisms of placebo analgesia: Expectancy theory and classical conditioning. PhD thesis, University of Connecticut, 1996.

45. James JE, Hardardottir D. Influence of attention focus and trait anxiety on tolerance of acute pain. Br J Health Psychol 2002;7:149-62.

46. Lindgren R. [Depression in the Elderly. Psychiatric Aspects of Young Women with Breast Cancer.] Goteborg: Organon, 2002.

47. Fine PG, Roberts WJ, Gillette RG, Child TR. Slowly developing placebo responses confound tests of intravenous phentolamine to determine mechanisms underlying idiophatic chronic low back pain. Pain 1994;56:235-42.

48. Montgomery GH, Kirsch I. Mechanisms of placebo pain reduction: An empirical investigation. Psychol Sci 1996;7:174-6.

49. Kirsch I, Baker S. Clinical implications of expectancy research:
Activating placebo effects without deception. Contemp Hypn 1993;10:130-2.

50. Turkat ID, Adams HE. Covert positive reinforcement and pain modification: A test of efficacy and theory. J Psychosom Res 1982;26:191-201.

51. Jonssson H, Lundback K. [Life with Persistent Neuropathic Pain.] Umea: Umea Universitet, Institutionen for Omvardnad, 2000.

52. Killander E, Modig G, Nilsson G. [Belief in the Patient.] Lund: Studentlitteratur, 1999.

53. So S. [The Treatment of Persistent Pain.] Stockholm: Socialstyrelsen, 1994.

54. Achterberg J, Kenner C, Casey D. Behavioral strategies for the reduction of pain and anxiety associated with orthopedic trauma. Biofeedback Self Regul 1989;14:101-14.

55. Brose W, Spiegel D. Neuropsychiatric aspects of pain management. In: Hales RE, Yudofsky, SC, eds. Synopsis of Neuropsychiatry. Washington: American Psychiatric Press, 1994:205-29.

56. Crombez G, Vansteenwegen D, Baeyens F, Ecclestone C. [Attention! Pain. An experimental analysis of the interruptive function of pain.] Tijdschr Psychol Gezond 1998;26:1-15.

57. Harrington A. The placebo effect: An interdisciplinary exploration. Cambridge: Harvard University Press, 1997.

58. Lazarus RS. Toward better research on stress and coping. Am Psychol 2000;55:655-73.

59. Norlander T, Kjellgren A, Archer T. Effects of flotation versus chamber-restricted environmental stimulation technique (REST) on creativity and realism under stress and non-stress conditions. Imagination, Cognition and Personality 2003;22:341-57.

60. Kjellberg A, Iwanowski S. [The Stress/Energy Questionnaire: Development of a Method to Evaluate Mood at Work.] Solna: Arbetsmiljoinsititutet, 1989.

61. Iwanowski S. [Testing the Adjective Checklist.] Solna: Arbetsmiljoinstitutet, 1989.

62. Kjellberg A, Bohlin A. Self-reported arousal: Further development of a multi-factorial inventory. Scand J Psychol 1974;15:285-92.

63. Nowlis V, Green BE. Research with the mood adjective checklist. In: Tomkins SS, Ixard CE, eds. Affect, Cognition and Personality. New York: Springer, 1965:352-89.

64. Zigmond AS, Snaith RP. The hospital anxiety and depression scale. Acta Psychiatr Scand 1983;67:361-70.

65. Herrmann C. International experiences with the hospital anxiety and depression scale - a review of validation data and clinical results. J Psychosom Res 1997;42:17-41.

65. Scheier MF, Carver CS. Optimism, coping, and health: Assessment and implications of generalized outcome expectancies. Health Psychol 1985;4:219-47.

66. Norlander T, Bergman H, Archer T. Relative constancy of personality characteristics and efficacy of a 12-month training program in facilitating coping strategies. J Soc Behav Pers 2002:30;773-84.

67. Kercher K. Assessing subjective well-being in the old-old: The PANAS as a measure of orthogonal dimensions of positive and negative affect. Res Aging 1992;14:131-68.

68. Norlander T, Bood SA, Archer T. Performance during stress by different occupational groups: Affective personality, age and regularity of physical exercise. Soc Behav Pers 2002;30:495-508.

69. Bood SA, Archer T, Norlander T. Affective personality in relation to general personality, self-reported stress, coping and optimism. Ind Diff Res 2004;2:26-37.

70. Watson D, Clark LA, Tellegen A. Development and validation of brief measures of positive and negative affect: The PANAS scale. J Pers Soc Psychol 1988;54:1063-70.

71. Huebner ES, Dew T. Preliminary validation of the positive and negative affect schedule with adolescents. J Psychoeduc Ass 1995; 13:286-93.

72. Kjellgren A. The experience of flotation-REST (restricted environmental stimulation technique): Consciousness, creativity, subjective stress and pain. PhD thesis, Goteborgs Universitet, 2003.

73. Crombie IK, Davies HT, Macrae WA. The epidemiology of chronic pain: Time for new directions. Pain 1994;57:1-3.

74. Damasio AR. Emotion in the perspective of an integrated nervous system. Brain Res Rev 1988;26:83-6.

75. Gustafsson M. [Education in persistent pain.] Stockholm: Svensk Sjukskoterskeforening, 2002.

76. Hall-Lord ML. [Elderly patients' experiences of pain and distress from the patients' and nurses' point of view.] Goteborg: Goteborg Universitet, 1999 


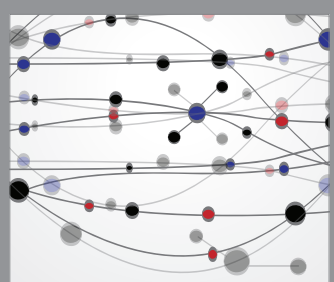

The Scientific World Journal
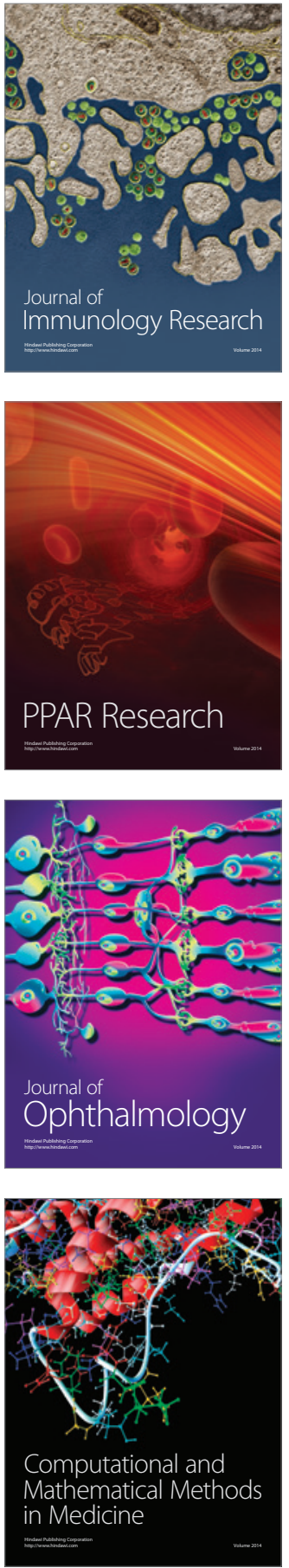

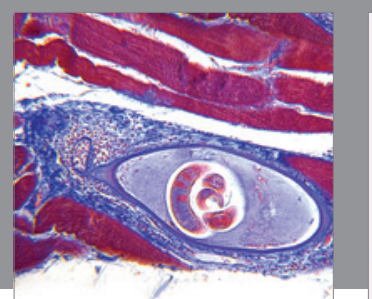

Gastroenterology Research and Practice

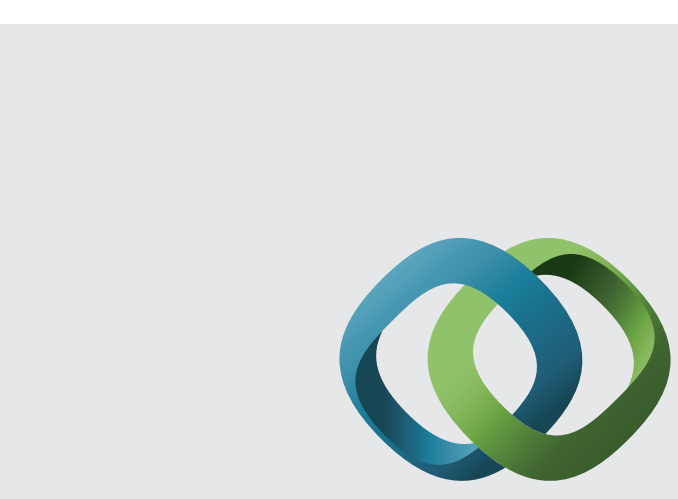

\section{Hindawi}

Submit your manuscripts at

http://www.hindawi.com
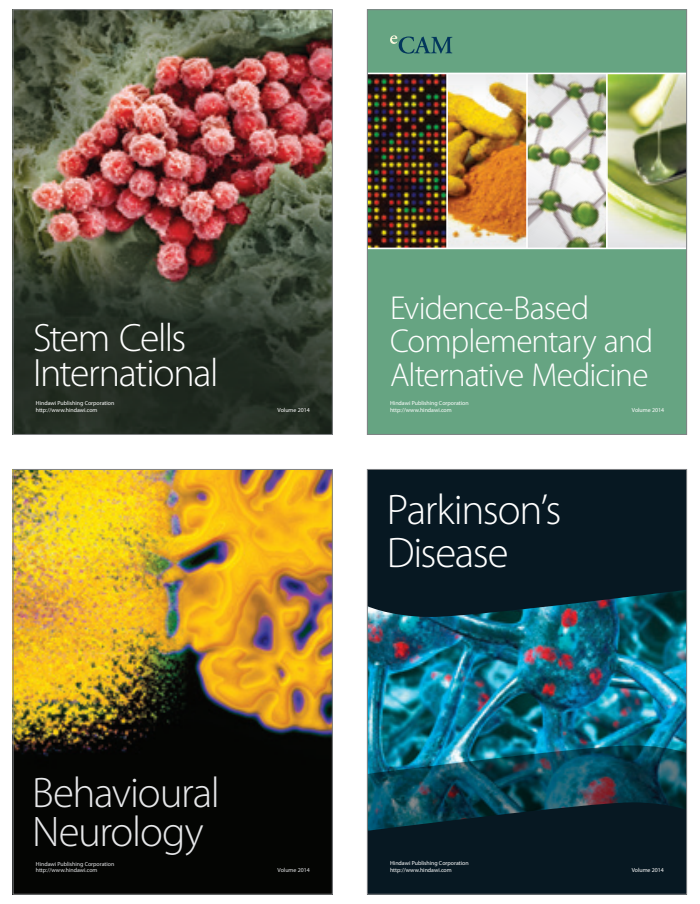
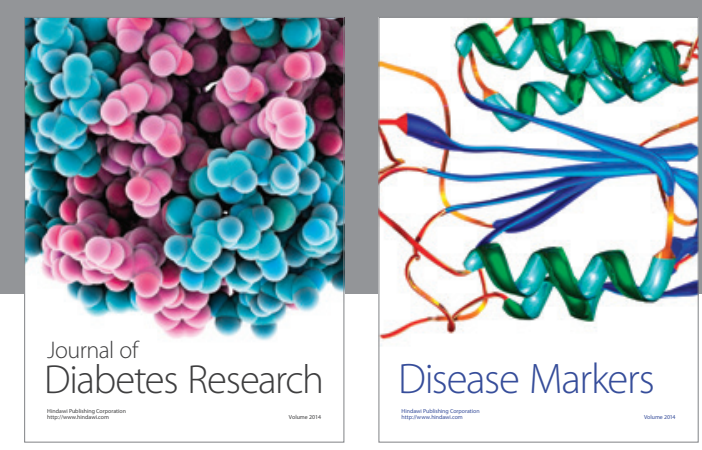

Disease Markers
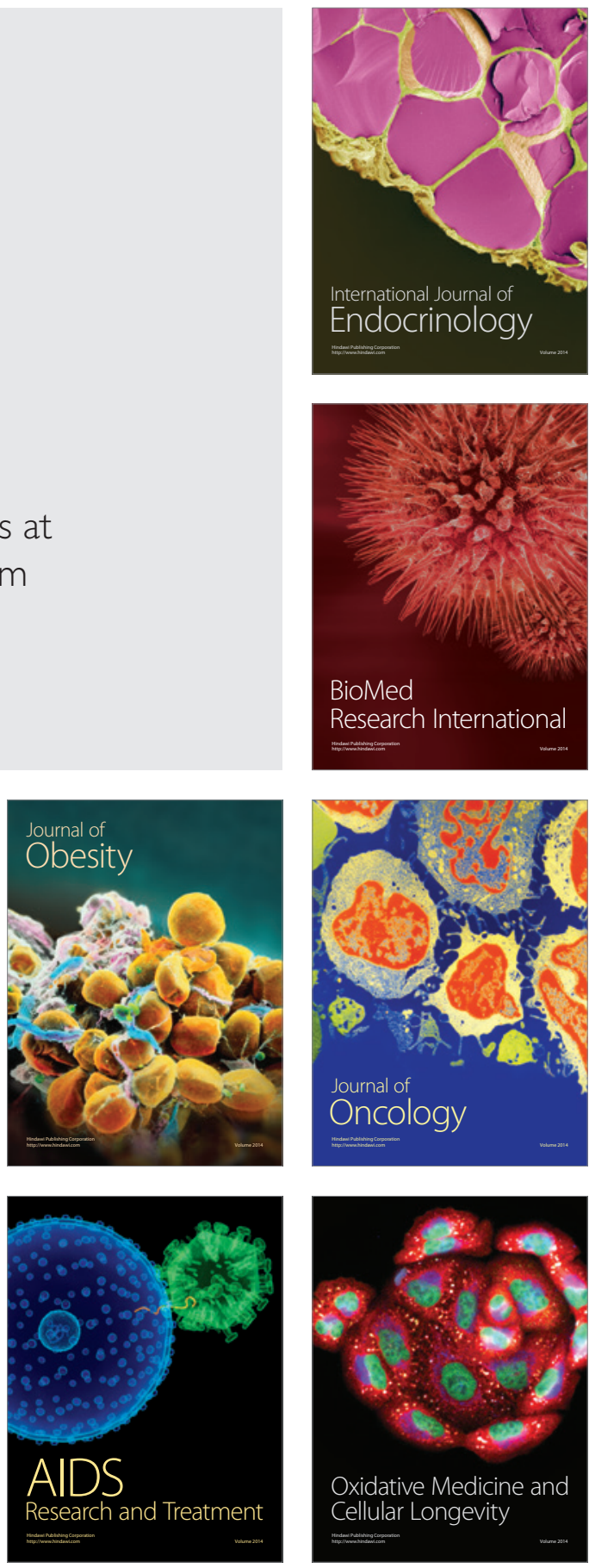